\title{
EDITORIAL
}

\section{LA SOCIEDAD DEL CONOCIMIENTO}

Los tiempos en que vivimos se denominan sociedad del conocimiento. Hemos dejado atrás la era del progreso, en la que la fuente de las ventajas de una sociedad o una organización era el acervo de capital o trabajo disponible. Hoy la fuente de la ventaja competitiva reside en la capacidad para adquirir, transmitir y aplicar conocimientos.

Hoy la información no está disponible solo para grupos reducidos de investigadores como en el pasado, sino que se encuentra al alcance de centenares de millones de personas, a través de Internet. Al promediar el año 2000 se podía acceder a 2.500 millones de páginas electrónicas y esta base de datos crecía a una tasa de 210 millones de páginas por mes.

Por otro lado, en el ámbito de las publicaciones científicas, el incremento del conocimiento no es menos dramático, existiendo en la actualidad 100 mil publicaciones científicas, comparadas a las 10 mil que circulaban durante el siglo pasado.

Es un hecho insoslayable que el conocimiento crece en forma alucinante. Si tomamos como base de referencia los veinte siglos de la era cristiana, tomó 1750 años para que el conocimiento se duplicara por primera vez. Hoy éste lo hace cada 5 años y hacia 2020, se estima que la cantidad de conocimiento se doblará en cantidad cada 73 días.

Ante esta realidad, como sucedió en los albores de los tiempos modernos y más tarde con el advenimiento de la era del progreso y la tecnología, la misión de la Universidad y quienes la conforman, reside en potenciar los procesos de formación humana y profesional, adecuándolos al nuevo paradigma, para así enfrentar con éxito los desafíos del presente y los dilemas que nos deparará la sociedad en el futuro.

Así como el nuevo orden impone condiciones al proceso de educación y formación profesional de las nuevas generaciones, éste será extremadamente exigente respecto de la competitividad y vigencia de los conocimientos de los profesionales graduados quienes, de no ser incorporados a un programa de educación continua, que además de actualizar sus conocimientos profesionales, les entregue un nivel de competencia mínima en el uso del idioma inglés, la tecnología digital y la comunicación global, quedarán irremisiblemente marginados de los centros de actividad científica y económica.

Hoy la Universidad tiene la responsabilidad de ofrecer carreras orientadas hacia el cumplimiento estándares de desempeño de carácter global, en las que, junto a una rigurosa formación profesional y humana, se incorporen el liderazgo, el emprendimiento, el uso del idioma inglés y de la tecnología, ofreciendo una formación en la que se fundan los conocimientos y las competencias propias de las profesiones, con las destrezas y habilidades necesarias para interactuar con eficacia y eficiencia en la sociedad del conocimiento.

Las universidades de países emergentes, en especial aquellos situados en Latinoamérica, necesitan estar conscientes del nuevo paradigma. Solo así podrán transformar las amenazas presentes en oportunidades, que les permitan insertarse de mejor modo en la nueva sociedad, en la que ya estamos viviendo.

Dr. Emilio Rodríguez Ponce 